\title{
Lithological Characterization by Simultaneous Seismic Inversion in Algerian South Eastern Field
}

\author{
Said Eladj \\ Department of Geophysics (LABOPHYT) \\ University M'hamed Bougara \\ Boumerdes, Algeria \\ s.eladj@univ-boumerdes.dz \\ Mohamed Zinelabidine Doghmane \\ Department of Automation (LAA) \\ University M'hamed Bougara \\ Boumerdes, Algeria \\ m.doghmene@univ-boumerdes.dz
}

\author{
Tanina Kenza Lounissi \\ Department of Geophysics (LABOPHYT) \\ University M'hamed Bougara \\ Boumerdes, Algeria \\ t.lounissi@univ-boumerdes.dz \\ Mabrouk Djeddi \\ Department of Geophysics (LABOPHYT) \\ University M'hamed Bougara \\ Boumerdes, Algeria \\ m.djeddi@univ-boumerdes.dz
}

\begin{abstract}
The main goal of this paper is to characterize a reservoir situated in the southeast of Algeria based on AVO seismic inversion. The seismic inversion model has been built by the iterative method of Aki and Richards's approximation and it has been correlated with four-existing wells in the studied zone. The correlation rate between the inversion model and logging data is good (varying from $72 \%$ to $85 \%$ ). Reservoir characterization of this field has been given in detail. The lithological description is used to construct a Geomechanical model that is useful for new wells' drilling decisions. The high correlated results allowed us to have a vision on the horizontal variation of Petrophysical parameters such as density and lithological variation of three facies clay, tight limestone, and porous limestone. Moreover, this classification is used in the best way to determine the interesting zone with higher porosity values, so that the exploration strategy becomes more efficient with minimized uncertainties. Therefore, it is highly recommended to use the constructed model to propose new wells as well-5 in this study.
\end{abstract}

Keywords-AVO seismic inversion; reservoir evaluation; Aki and Richards approximation; lithological description; Algerian field; exploration strategy

\section{INTRODUCTION}

Hydrocarbon demands have considerably increased during the last decades. Indeed, we all depend in different ways on these products which are located at depths of several hundreds or thousands of meters in the porous medium of the rocks [1]. However, the daily hydrocarbons' extraction decreases their reserves. As a result, exploration activity has been conducted around the world in order to search for new fields. As the demand for energy increases, the gaze must be turned to littleknown complex reservoirs, where exploration and exploitation in the past were expensive and unprofitable. Nowadays, thanks to the technological advances in this field, the development of unconventional resources has become not only possible, but it also holds a primordial place in the oil industry [1].

Thus far, seismic reflection, which is the most used geophysical method, was only interested in information related to the structure. The geophysicists were interested only in the travel time interpretation of the seismic waves [2]. This led to several unsuccessful boreholes, guiding the geophysicists to pay particular attention to the secondary information that seismic data transmit: the amplitude. It was noticed that it could give indications on lithology and fluid content of the reservoirs. In the framework of new fields' exploration, the considered field in this study is situated in the southeast of Algeria. A study including seismic inversion model construction was conducted. It consists of inverting the seismic data before summation in order to highlight the differences in lithology and thus to better understand, characterize, and evaluate the reservoir [3, 4].

\section{SEISMIC INVERSION FOR THE STUDIED FIELD}

In this section, we will begin the application of seismic inversion on real seismic data. The study was carried out on the seismic data of the field situated in the southeast of Algeria, which contains four (4) cubes with four (4) different stack angles: $5-10^{\circ}, 10-20^{\circ}, 20-30^{\circ}$, and $30-40^{\circ}$ as shown in Figure $1[3,9]$. Four wells (W1, W2, W3, and W4) were drilled in the field as shown in Figure 2, where all necessary logging data (acoustic impedance (AI), $\mathrm{Vp} / \mathrm{Vs}$ velocity ratio, and density (Rhob)) are available. Based on the geological description of the region, core description, and drilling reports eight seismic horizons were confirmed: 1) Maastrichtian, 2) Campanian, 3) Santonian, 4) Coniacien, 5) Turonian, 6) Cenomanian, 7) Albian, and 8) Aptian (Figure 3). Detailed workflow of seismic inversion before summation, applied to the studied field, is given in Figure $4[5,6,9]$. 


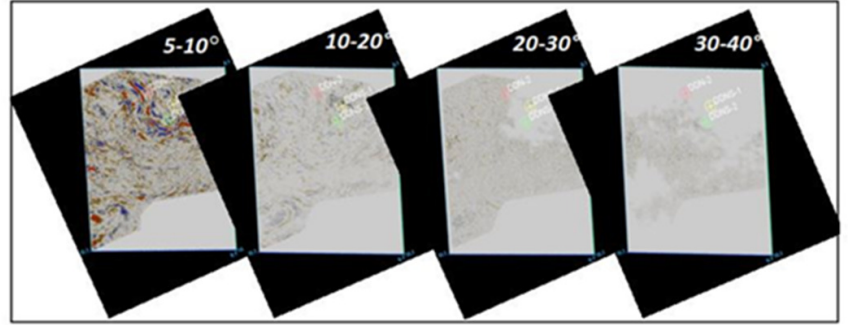

Fig. 1. Seismic cubes of the studied field with different stack angles

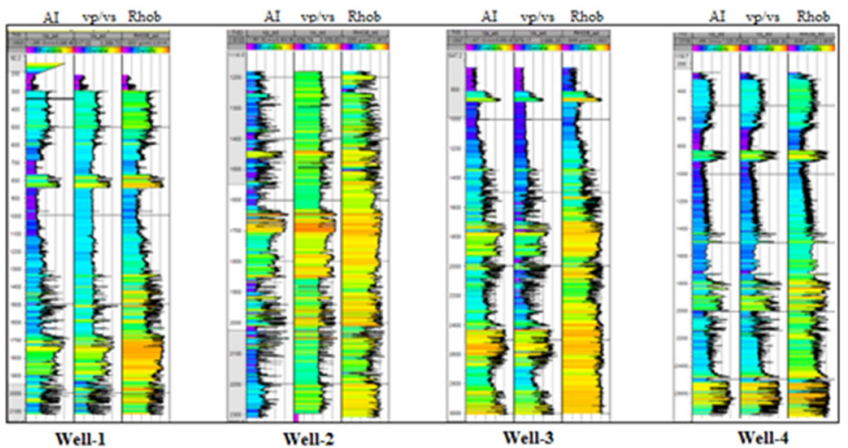

Fig. 2. Data of the four drilled wells of the studied field

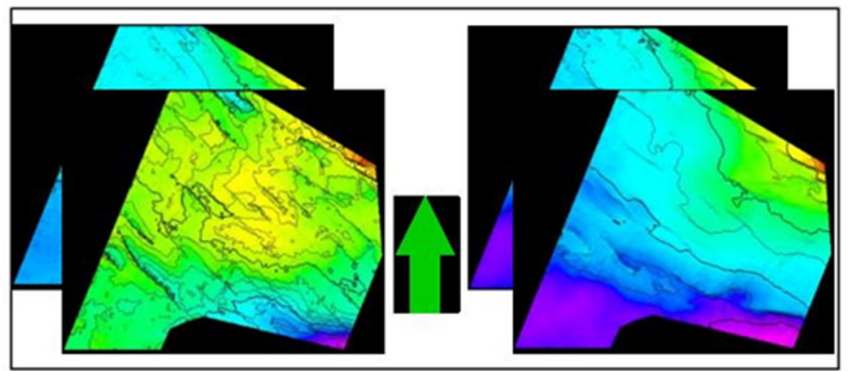

Fig. 3. The seismic horizons of the studied field

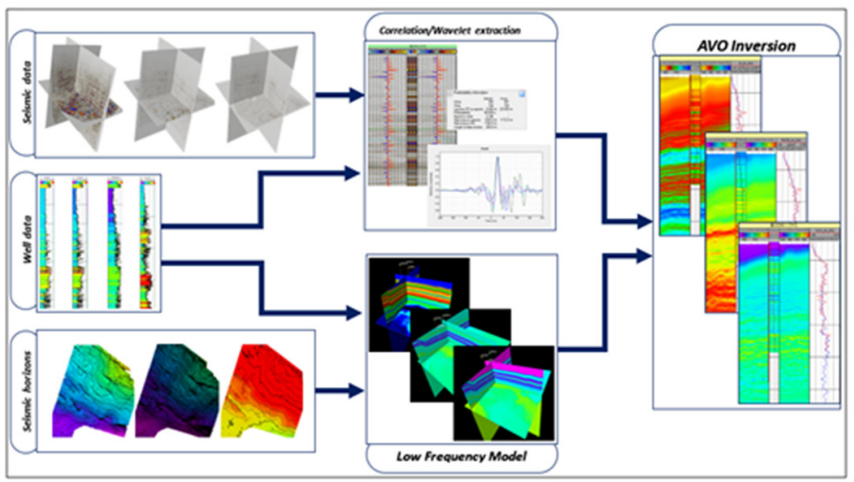

Fig. 4. Workflow of seismic inversion applied to the studied field

\section{ROY WHITE WAVELET EXTRACTION METHOD}

To extract the required wavelets and perform a seismic inversion, a seismic/well data correlation must be made in order to estimate the optimal wavelets $[3,7]$. To do this, we used the Roy White method, which consists of estimating a wavelet corresponding to the best correlation between the seismic/well data. This is done by calculating the coherence function $\mathrm{G}(\mathrm{m})$ expressed by:

$$
G(m)=\frac{\left[\sum_{f} R^{*}(m, f) \cdot S(f)\right]^{2}}{\sum_{f}\left[R^{*}(m, f) \cdot R(m, f)+s t a b\right] \sum_{f} S^{*}(f) \cdot S(f)}
$$

where $s(t)$ is the seismic trace, $r(t)$ is the reflectivity, $R(m, f)$ represents $r(t)$ shifted by $m$ samples related to $s(t)$ in the time domain, $f$ is the frequency, $S(f)$ is the Fourier transform of $s(t)$, and stab is a small factor that guarantees the stability of the coherence function. This function calculates the proportion of energy in the seismic traces that can be predicted by the well data $[8,10,11]$. The maximum of this function corresponds to the best alignment between the well and the seismic data, from which the wavelet is extracted by performing a simple deconvolution in the frequency domain [12]. The Roy White method estimates wavelet characteristics by correlating well and seismic data [11]. This method contains two main steps:

- Looking for the ideal position where we will have a perfect fit between the seismic and the reflectivity logs using the coherence function. The coherence function is essentially a cross-correlation between $r(t)$ and $s(t)$ normalized by their autocorrelation. The function measures the proportion of energy of the data that can be predicted from the reflectivity logs [12]. We will then seek the value of $N$ to maximize the coherence function as given in (2)

$$
G(N)=\operatorname{Max}[G(m)] ; \quad-M \leq m \leq M
$$

After shifting the reflectivity series by $N$, it will achieve the best match rate with the seismic data.

- Estimating the wavelet $W(t)$ at the best seismic/well match: The convolution equation in the frequency domain is expressed by:

$$
S(f)=R(N, f) \cdot W(f)
$$

Multiplying (3) by the term $R^{*}(N, f)$ on both sides, we find:

$$
R^{*}(N, f) \cdot S(f)=R^{*}(N, f) \cdot R(N, f) \cdot W(f)
$$

Equation (4) is divided by $R^{*}(N, f) \cdot R(N, f)$ on both sides, and a factor is added in the denominator in order to stabilize:

$$
W(f)=\frac{R^{*}(N, f) \cdot S(f)}{R^{*}(N, f) \cdot R(N, f)+s t a b}
$$

By calculating the inverse Fourier transform (IFT) of $W(f)$, we find the wavelet given by:

$$
W(t)=\operatorname{IFT}[W(f)]
$$

The advantage of Roy White method is that it makes the calculation of the predictability possible, besides the good quality of the correlation using the resulting formula [12]. The maximum residual energy, which represents the energy 
resulting from the difference between the synthetic film and the real data, is given as power index described by (7):

$$
P=1-\frac{\text { residual energy }}{\text { energy of a trace }}
$$

\section{A. Wavelets Extraction Results}

The results of the seismic/well data correlation and the extracted wavelets for Well-1 and Well-2, are illustrated in Figures 5 and 7 respectively. The extracted wavelets with different stack angles for Well-1 and Well-2 are shown in Figures 6 and 8 respectively.

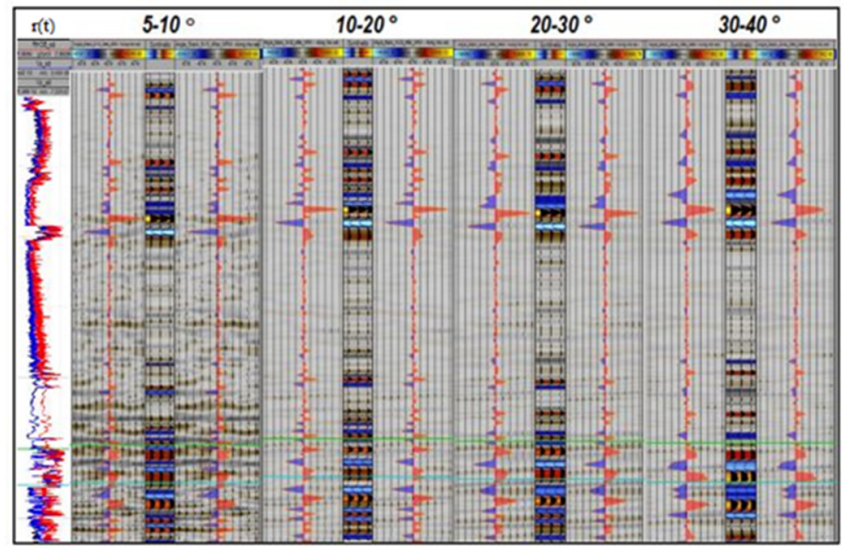

Fig. 5. Seismic/well data correlation results using extracted wavelets with different stack angles for Well-1

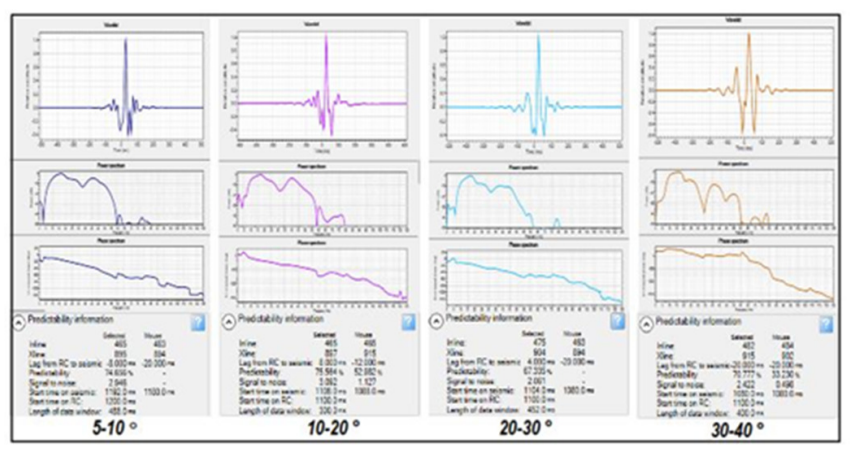

Fig. 6. Extracted wavelets with different stack angles for Well-1

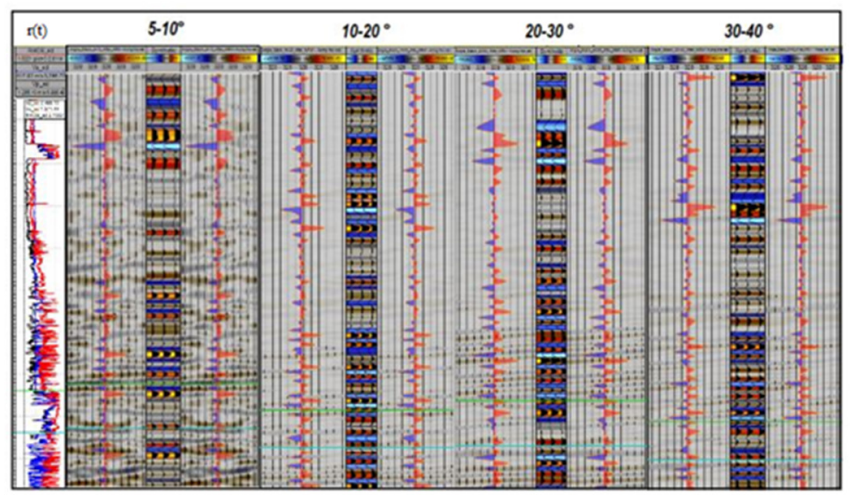

Fig. 7. Seismic/well data correlation results using extracted wavelets with different stack angles for Well-2

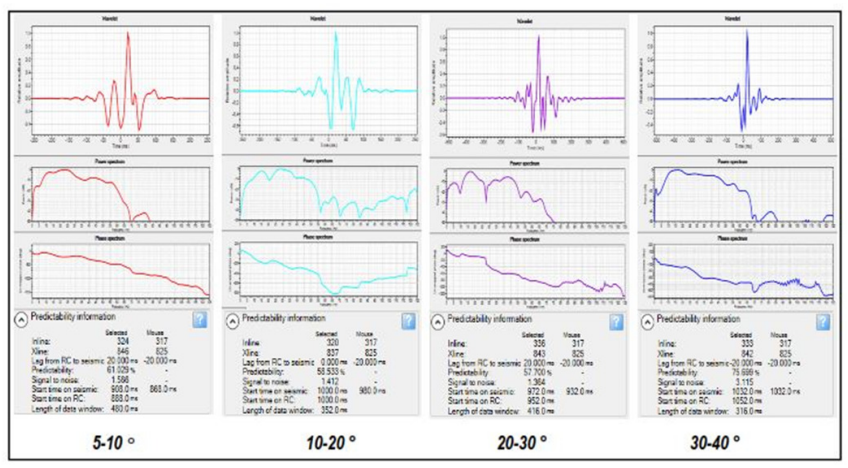

Fig. 8. Extracted wavelets with different stack angles for Well-2

\section{B. Wavelets Comparison}

1) By Wells

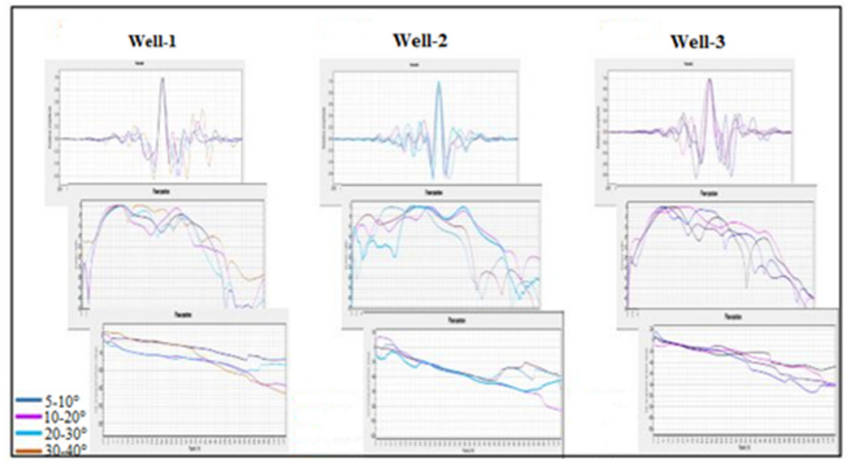

Fig. 9. Comparison between extracted wavelets for Wells 1, 2, and 3

\section{2) By Stack Angle}

After comparing the extracted wavelets for different Wells and for different stack angles in Figures 9 and 10, it is noticed that they are stable, and that the energy peaks are similar when the different wavelets are overlapped and that the amplitude spectrum is also stable too. Thus, we can calculate the average wavelet from wavelets for each stack angle to estimate the appropriate wavelet as shown in Figure 11.

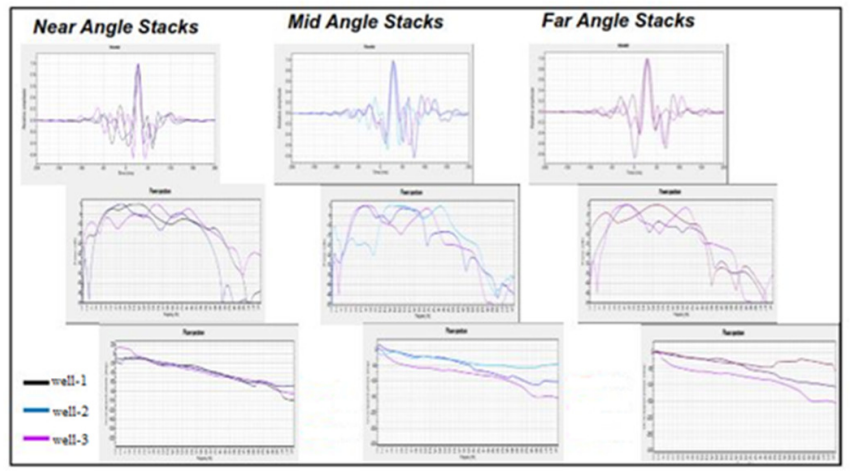

Fig. 10. Comparison of the extracted wavelets for different stack angles

\section{Low Frequency Model Generation}

Since the inversion is iterative, a starting model is required. It can be obtained by interpolating and/or extrapolating the data 
of wells according to the seismic horizons [3]. The model must then be filtered to keep only the low frequencies missing from the frequency spectrum of the seismic data, taking care not to suppress other frequencies [12-14]. For this purpose, a mean frequency spectrum corresponding to the seismic data is generated (Figure 12). We can notice that up to $10 \mathrm{~Hz}$, the energy of the seismic signal is very low. To confirm this remark, a series of filtering is applied to the seismic data as shown in Figure 13 [13, 14].

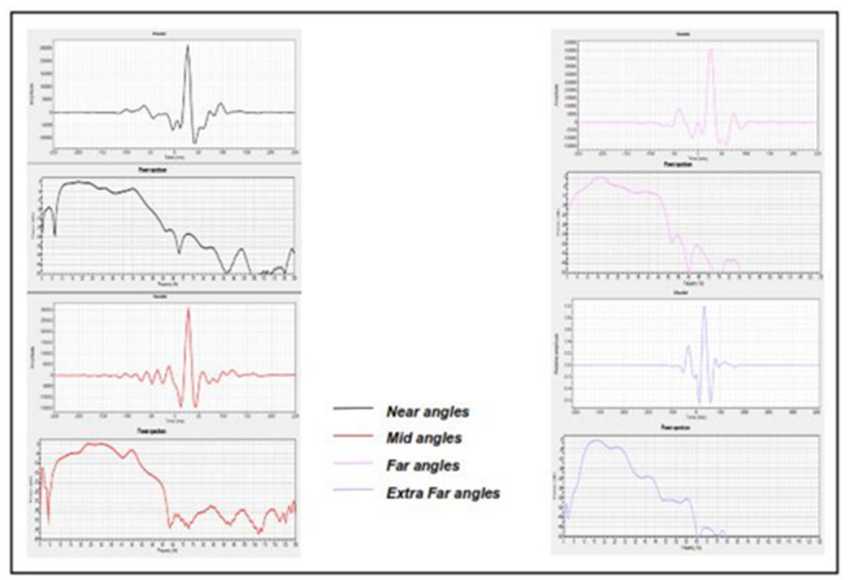

Fig. 11. Average wavelet for each stack angle

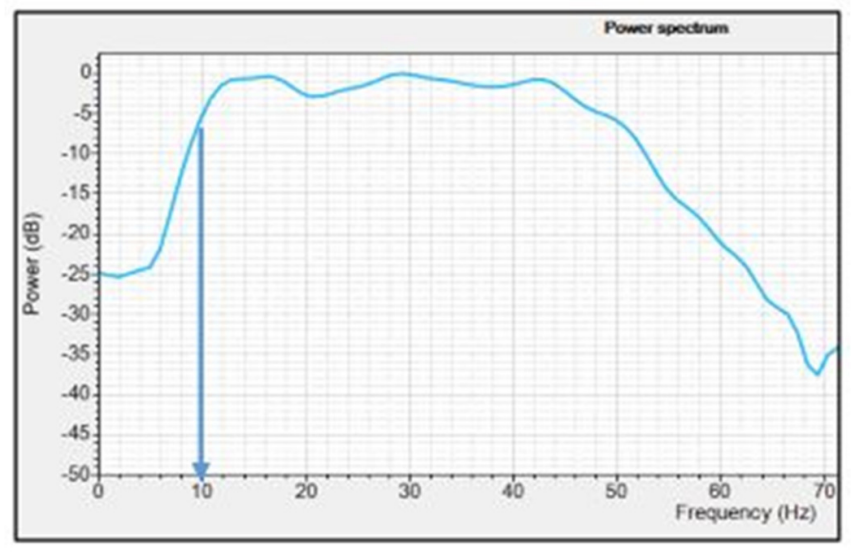

Fig. 12. Average frequency spectrum of seismic data

We notice from Figure 13 that at $12 \mathrm{~Hz}$ the signal remains powerful, at $8 \mathrm{~Hz}$ the signal disappears, and at $10 \mathrm{~Hz}$ the signal is extremely weak, so the low pass filter retained and it will be used. Thus, the missing frequencies of the seismic data, which will be recovered by the well data, are the frequencies below $10 \mathrm{~Hz}[13,14]$. The solution of nonlinear inverse problems is obtained by the iterative method that implies a determination of an initial model as a starting point. The initial model must contain prior information from well logs, geological coring, and structural interpretation of seismic data. These data should be as loyal as possible to reality (carrots, cores description) so that they facilitate the search for the minima of the cost function. In our case study, the algorithm is based on the global minimum search, so the solution will not depend strongly on the initial model. Nevertheless, its good estimation will make the search of the global minima faster. The construction of the initial model is done by interpolation and extrapolation of the well data with the resulting seismic horizons from the seismic interpretation. We then apply a lowpass filter to keep only the low frequencies $[13,14]$. Well data are used because they cover a wider frequency window $(0-500 \mathrm{~Hz})$ in comparison to seismic data $(5-65 \mathrm{~Hz})$, allowing us to recover the missing low values of the seismic frequency band and reinforce our model by adding the low frequencies $(0-10 \mathrm{~Hz})$. These missing frequencies are either not recorded during the seismic acquisition or they were lost during data processing. Moreover, they will allow us after inversion to recover the absolute acoustic impedances [3]. The main challenge is how to widen the frequency band of the initial model in terms of frequency without overwriting some low frequencies already contained in the seismic data. Therefore, this guarantees that the inversion result matches the well data. We have to find the cut-off frequency that will allow optimizing our global minima search problem.

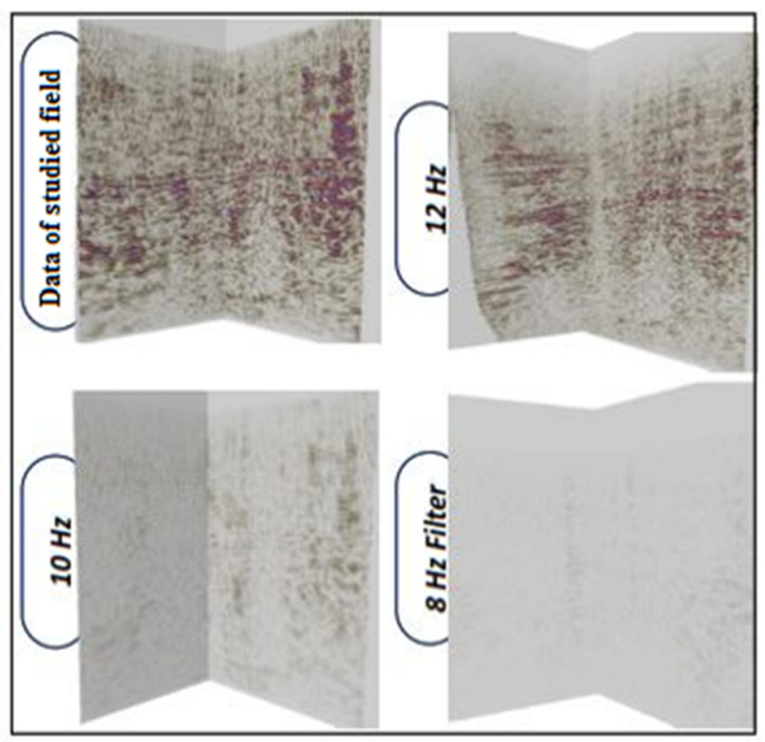

Fig. 13. Different filters applied to the seismic data

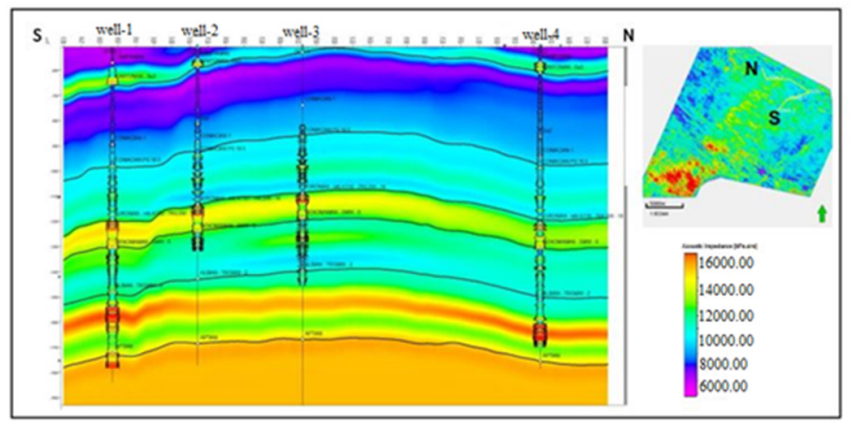

Fig. 14. Low frequency acoustic impedance model

\section{SEISMIC INVERSION RESULTS}

The inversion is done by iterative method according to a global optimization algorithm. The cost function to optimize is the Global Seismic Inversion. The results of seismic inversion 
for AI, $V p / V s$, and density models are shown in Figure 17, 18, and 19 respectively. The quality control of wells data used for correlation is given in Figures 20-23.

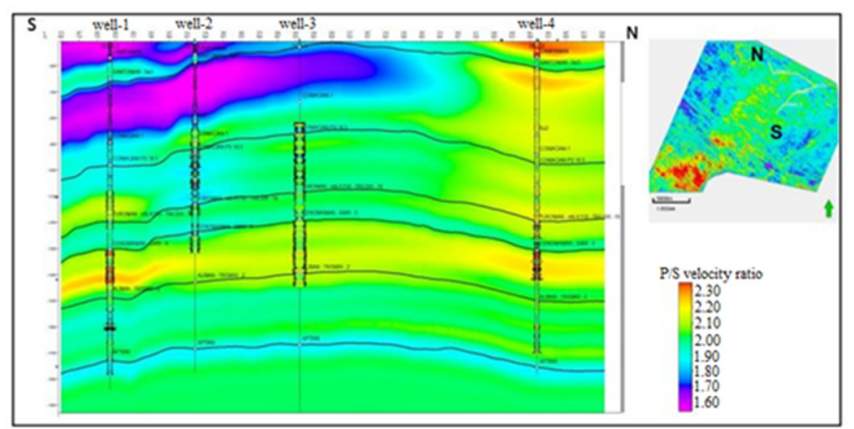

Fig. 15. Low frequency $V p / V s$ model

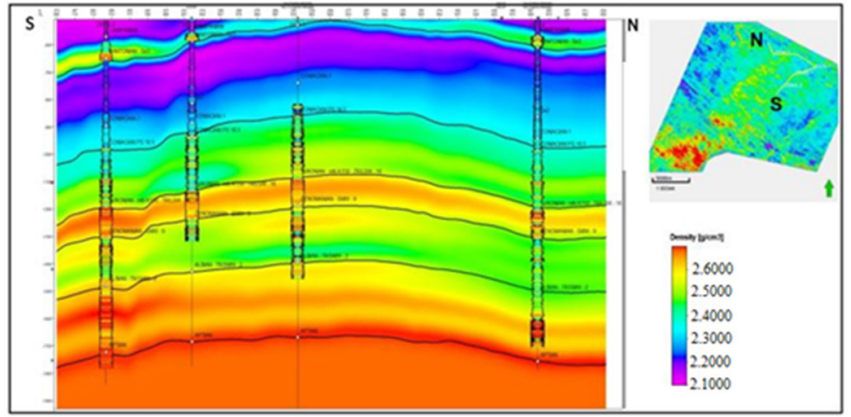

Fig. 16. Low frequency density model

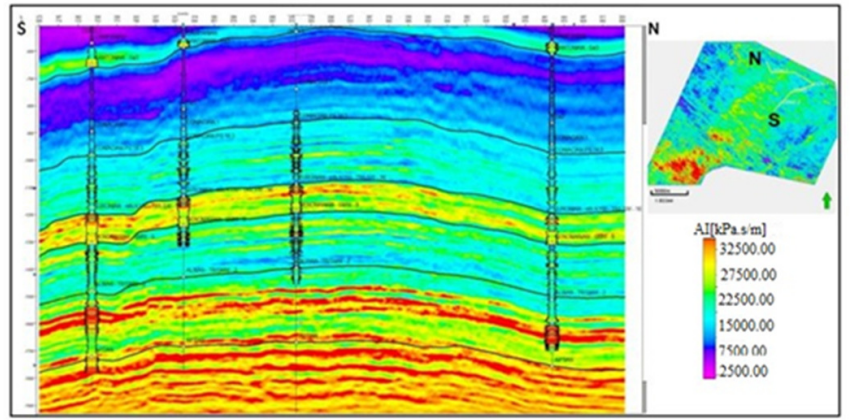

Fig. 17. Seismic inversion result for the acoustic impedance model

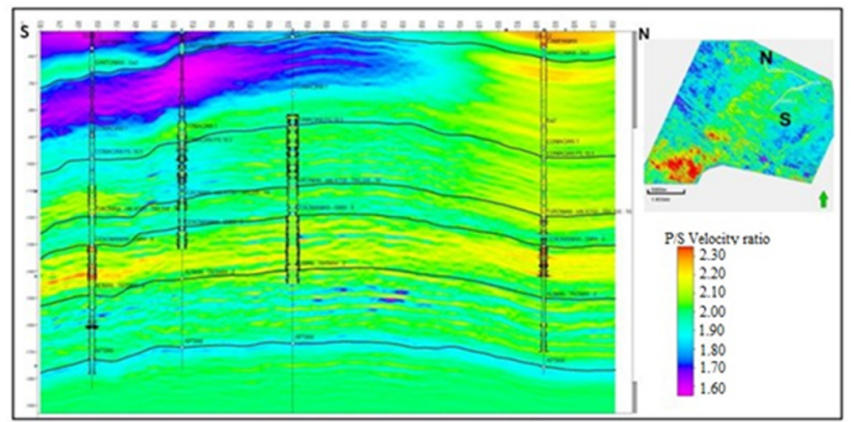

Fig. 18. Seismic inversion result for the $V p / V s$ model

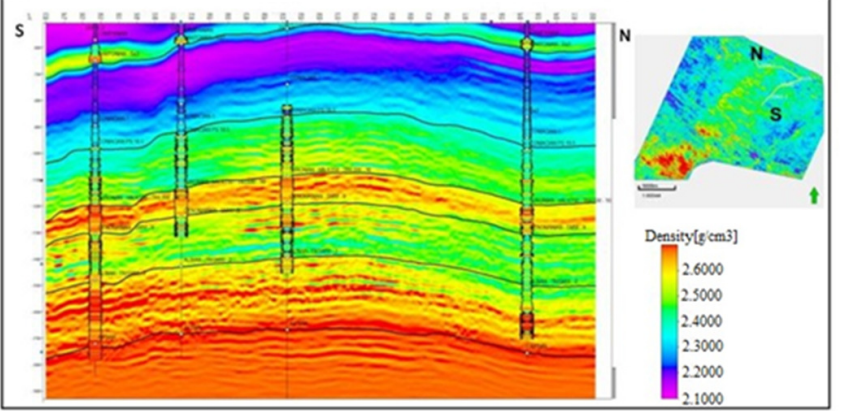

Fig. 19. Seismic inversion result for the density model

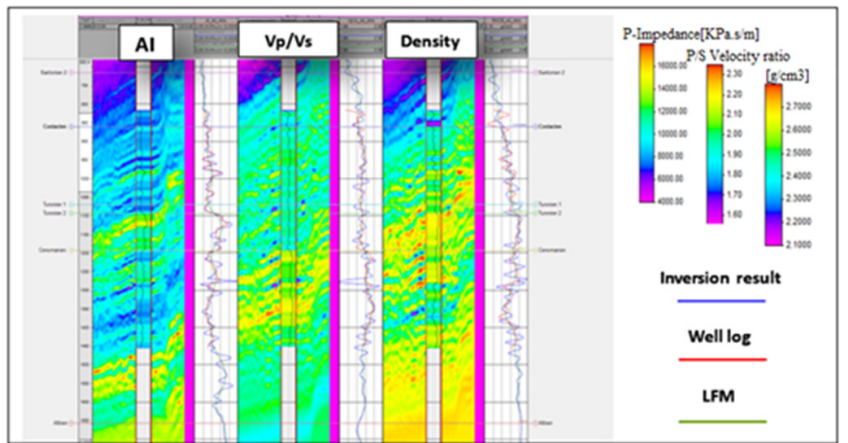

Fig. 20. Comparison of the inverse model with Well-1 data

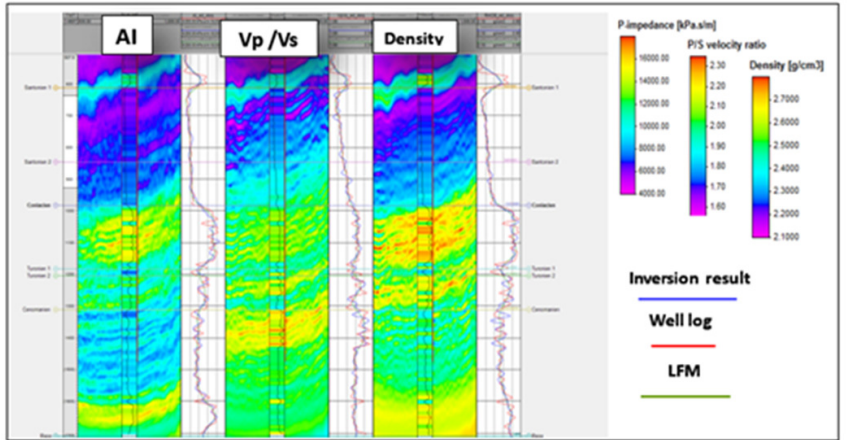

Fig. 21. Comparison of the inverse model with Well-2 data

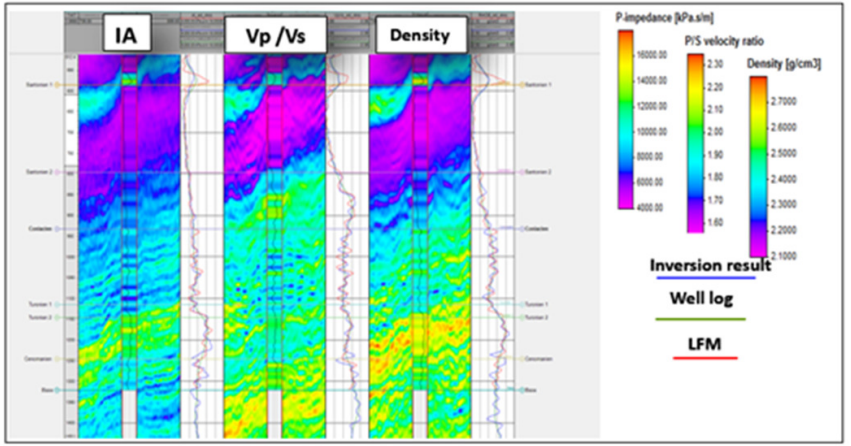

Fig. 22. Comparison of the inverse model withWell-3 data

We can clearly see an acceptable correlation between the profiles of the logging data for the different wells, shown in red in Figures 20-23 and the profiles of the results of the seismic 
inversion before summation in blue. We are therefore able to conclude that the various parameters allowing the inversion of the seismic data have been well optimized, namely: a) the wavelets, b) the low frequency model, and c) the different weights related to the cost function.

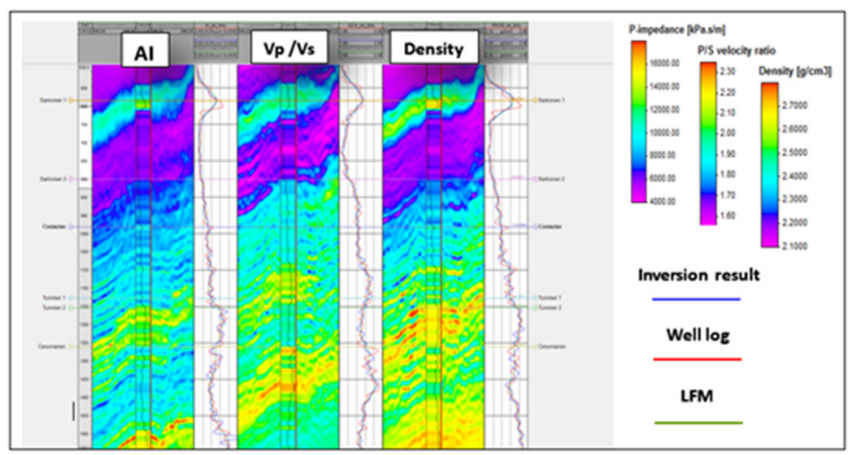

Fig. 23. Comparison of the inverse model with Well-4 data

\section{RESERVOIR CHARACTERIZATION}

After performing a simultaneous inversion of the seismic data, and comparing its results with well logging data, we can see that the parameter estimation is acceptable and that the results of the inversion correspond to the well data. Therefore, we can use these results to determine the type of existing lithology and their characteristics [15]. The characterization of the reservoir in terms of fluid content and lithological indication is very important, so we characterized the reservoir by using its lithological properties [16]. To achieve a lithological classification of the reservoir, different crossplots of the parameters resulting from the inversion (AI, $V p / V s$ and density) were performed, and an example is given in Figure 24 [17]. We can clearly notice that all points are overlapped, thus, no conclusions can be extracted from this crossplot. Another method should be used, which will be supported by the results of the petrophysical interpretation of the well data.

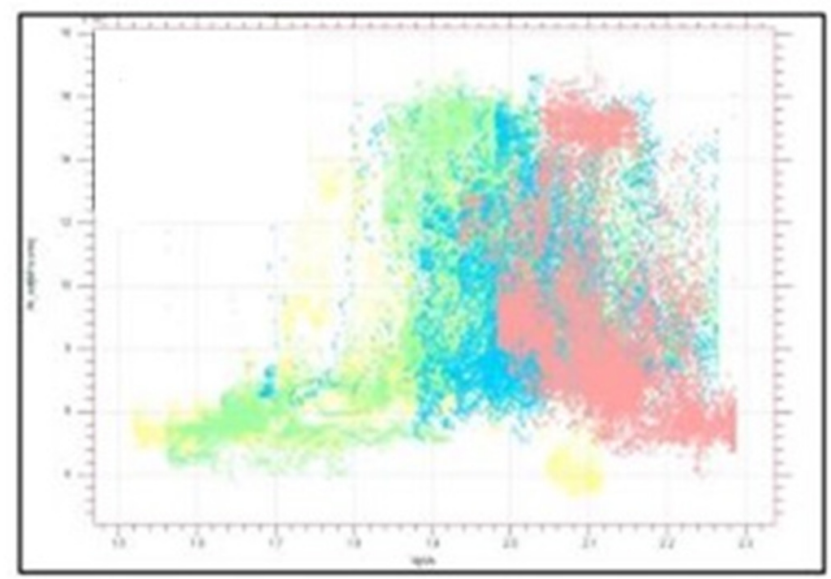

Fig. 24. Crossplot of $A I=f(V p / V s)$

We can classify lithology based on the following conditions: Clay: if Vshale $>0.2$, Tight Limestone: if Vshale $<0.2$ and $P H I<0.05$, Porous limestone: if Vshale $<0.2$ and
PHI $>0.05$ [18]. These three conditions will be generalized on the entire volume from the logs, so, three classes will stand out $[19,20]$. These classes are represented first by probability density functions given in Figure 25 [16].

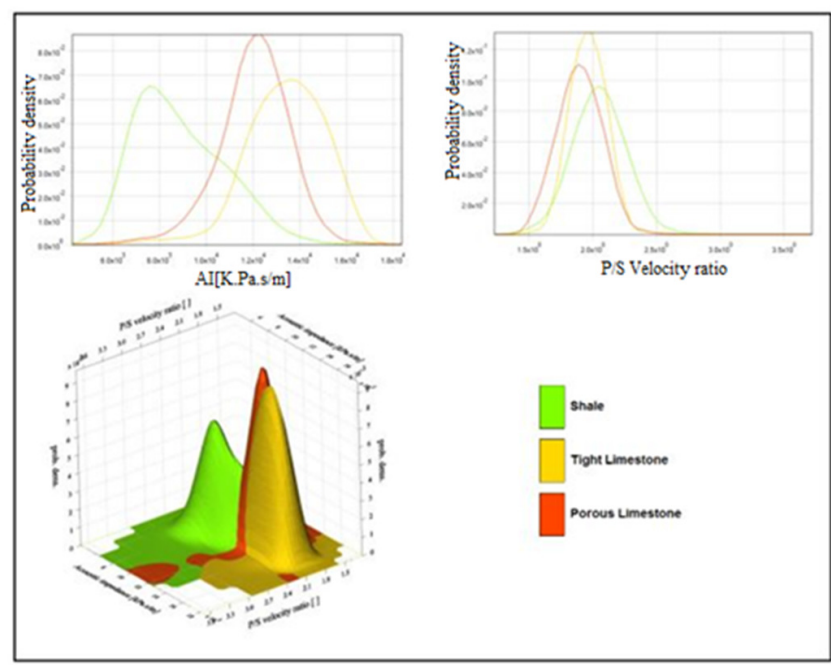

Fig. 25. Probability density functions of the three lithology classes

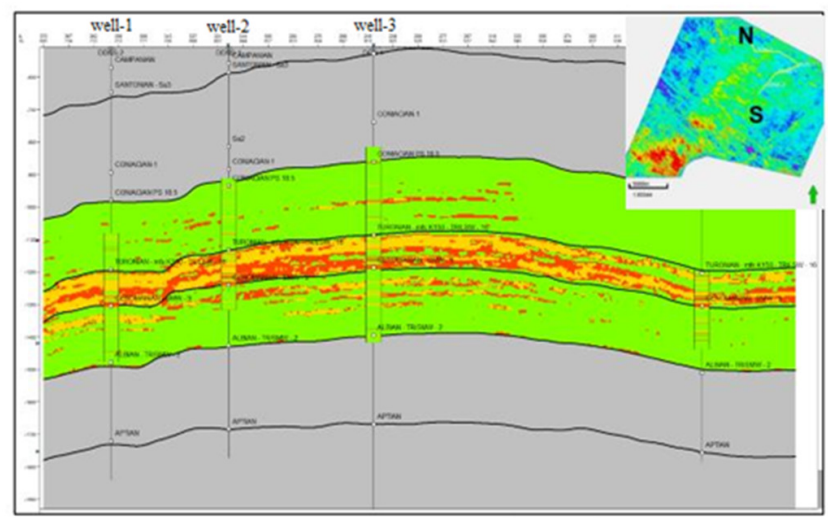

Fig. 26. Crossline passing through the four wells showing the results of lithology classification

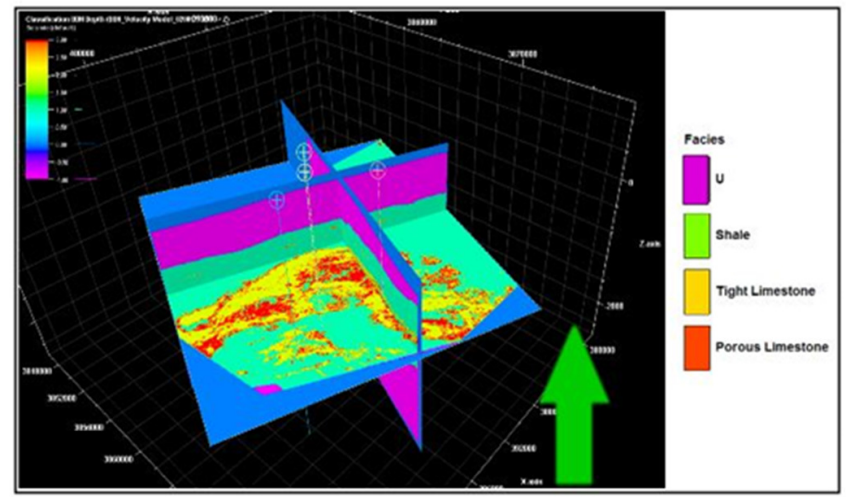

Fig. 27. Lithology classes resulting from the characterization illustrated on the whole seismic volume 
The results of lithological classification are shown in the Figures 26 and 27. In Figure 26, we see a crossline passing through the four wells. The obtained lithology model shown in Figure 27 allows us to determine the porous zones (shown in red) in which there is a high probability of presence of hydrocarbons [21]. Indeed, based on this study, a decision of drilling well (Well-5) has been made and its productivity is under evaluation.

\section{CONCLUSIONS}

In this paper, we have been able to highlight the importance and utility of the seismic inversion for reservoir characterization. It consists of determining the lithology in order to define the most appropriate locations for potential drilling. Several factors were considered for reliable seismic inversion. The key element is the good estimate of the seismic wavelet which is the direct link between the lithology and the seismic data. The Roy White method is a good approach of estimation in this region since the seismic/well correlation has acceptable values ranging from $72 \%$ to $85 \%$. The nonuniqueness of the solution of the inverse problem constitutes an important obstacle, but the generation of a low frequency initial model from well data and horizons resulting from the structural interpretation of the seismic data allowed circumventing this problem, thus bringing useful information in order to force the algorithm to converge towards the optimal solution. Simultaneous inversion of the seismic data results in AI, $V p / V s$, and density volumes are very important for identifying lithology. From these parameters several seismic attributes can be calculated and will serve in reinforcing the interpretation in terms of lithology and fluid content and the decision making for exploration drilling.

\section{ACKNOWLEDGMENT}

This study has been sponsored by DGRSDT (Direction Generale de la Recherche Scientifique et de Developpement Technologique), Algiers-Algeria.

\section{REFERENCES}

[1] B. Goodway, M. Perez, J. Varsek, C. Abaco, "Seismic petrophysics and isotropic-anisotropic AVO methods for unconventional gas exploration", The Leading Edge, Vol. 29, No. 12, pp.1500-1508, 2010

[2] Y. Wang, "Seismic amplitude inversion in reflection tomography", in: Handbook of geophysical exploration: seismic exploration, Vol. 33, Pergamon, 2003

[3] P. Chen, E. J. Lee, Full-3D seismic waveform inversion: theory, software and practice, Springer, 2015

[4] M. Sengupta, J. Dai, S. Volterrani, N. Dutta, N. S. Rao, B. Al-Qadeeri, V. K. Kidambi, "Building a seismic-driven 3D geomechanical model in a deep carbonate reservoir", in: SEG Technical Program Expanded Abstracts, SEG San Antonio Annual Meeting, pp. 2069-2073, SEG, 2011

[5] X. Xao, T. Jenakumo, C. Ash, H. Bui, O. Fakunle, S. Weaver, "An integrated workflow combining seismic inversion and 3D geomechanics modeling: Bonga Field, Offshore Nigeria", Offshore Technology Conference, Houston, USA, 2-5 May, 2016

[6] H. B. Russell, "Prestack seismic amplitude analysis: An integrated overview", Interpretation, Vol. 2, No. 2, pp. SC19-SC36, 2014

[7] R. P. Bording, "Seismic wave propagation: modeling and inversion", in: Seismic modeling and imaging with the complete wave equation, Society of Exploration Geophysicists, 1997
[8] M. Fohrmann, I. A. Pecher, "Analysing sand-dominated channel systems for potential gas-hydrate-reservoirs using an AVO seismic inversion technique on the Southern Hikurangi Margin, New Zealand", Marine and Petroleum Geology, Vol. 38, No. 1, pp. 19-34, 2012

[9] L. Giroldi, B. Wallick, A. Rodriguez-Herrera, N. Koutsabeloulis, D. Lowden, "Applications of broadband seismic inversion in the assessment of drilling and completion strategies: A case study from eastern Saudi Arabia”, 2014 SEG Annual meeting, Denver, USA, October 26-31, 2014

[10] S.A. Ouadfeul, L. Aliouane, S. Eladj, "Multiscale analysis of geomagnetic data using the continuous wavelet transform: A case study from Hoggar (Algeria)", in: SEG technical program expanded abstracts 2010, pp. 1222-1225, Society of Exploration Geophysicists, 2010

[11] S. A. Ouadfeul, L. Aliouane, M. Hamoudi, A. Boudella, S. Eladj, "Multiscale analysis of geophysical signals using the 2D continuous wavelet transform", in: Wavelet transforms and their recent applications in Biology and Geosciences", Scitus Academics LLC, 2012

[12] Y. Wang, Seismic inversion: theory and applications, Wiley Blackwell, 2017

[13] J. Ferahtia, T. Aifa, K. Baddari, N. Djafour, S. Eladj, "Image-based processing techniques applied to seismic data filtering", Journal of Petroleum Science and Engineering, Vol. 104, pp. 17-26, 2014

[14] N. Djafour, J. Ferahtia, F. Babaya, K. Baddari, S. Eladj, M. Farfour, "Seismic noise filtering based on generalized regression neural networks", Computers and Geosciences, Vol. 69, pp. 1-9, 2014

[15] C. Convers, Prediction of reservoir properties for Geomechanical analysis using 3-D seismic data and rock physics modeling in the Vaca Muerta Formation, Neuquen Basin, Argentina, MSc Thesis, Colorado School of Mines, 2017

[16] M. Z. Doghmane, B. Belahcene, M. Kidouche, "Application of improved artificial neural network algorithm in hydrocarbons' reservoir evaluation", in: Lecture notes in networks and systems, Vol. 62, Renewable energy for smart and sustainable cities: artificial intelligence in renewable energetic systems, pp. 129-138, Springer, 2019

[17] K. Duffaut, M. Landro, "Vp $V$ s ratio versus differential stress and rock consolidation: A comparison between rock models and time-lapse AVO data", Geophysics, Vol. 72, No. 5, pp. C81-C94. 2007

[18] F. A. Neves, A. Al-Marzoug, J. J. Kim, E. L. Nebrija, "Fracture characterization of deep tight gas sands using azimuthal velocity and AVO seismic data in Saudi Arabia", The Leading Edge, Vol. 22, No. 5, pp. $469-475,2003$

[19] A. Sokhal, Z. Benaissa, S. A. Ouadfeul, A. Boudella, "Dynamic rock type characterization using artificial neural networks in Hamra quartzites reservoir: A multidisciplinary approach", Engineering, Technology, and Applied Science Research, Vol. 9, No. 4, pp. 4397-4404, 2019

[20] A. Jooybari, P. Rezaie, "Petrophysical evaluation of the Sarvak formation based on well logs in Dezful Embayment, Zagros Fold Zone, south west of Iran", Engineering, Technology, and Applied Science Research, Vol. 7, No. 1, pp. 1358-1362, 2017

[21] S. Eladj, M. Z. Doghmane, L. Aliouane, S. A. Ouedfeul, "Porosity model construction based on ANN and seismic inversion: A case study of Saharan Field in Algeria", 2nd Conference of Arabian Journal of Geosciences, Sousse, Tunisia, November 25-28 2019

\section{AUTHOR PROFILES}

Said Eladj was born in Meftah, Wilaya of Blida, Algeria. He obtained his

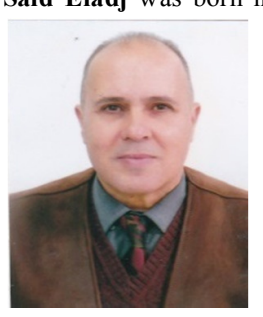
Geophysics PhD in 2007 from Lomonossov University of Moscow, Russia. He is an Associate Professor/Researcher at M'hamed Bougara University, Faculty of Hydrocarbons and Chemistry, Department of Geophysics, and the head of the Department since then. He is also the Head of a research team in the Laboratory of Physics of the Earth. His domains of interest include reservoir characterization by nonconventional techniques, seismic inversion, signal processing, and artificial neural networks in petroleum engineering. During his teaching experience he provides courses for $\mathrm{MSc}$ and $\mathrm{PhD}$ students in diagraphies, stratigraphic 
seismic, seismic prospection, artificial intelligence, and signal processing. Currently, he is directing more than $10 \mathrm{PhD}$ Theses and he is realizing a leading research project at the University of Boumerdes.

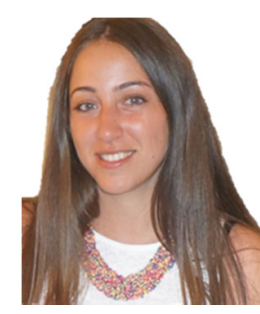

Tanina Kenza Lounissi was born in Algiers Algeria on November 17th, 1994. She graduated from the University of Boumerdes, Faculty of Hydrocarbons and Chemistry with an MSc degree in Petroleum Geophysics. Her research interests focus on seismic inversion and reservoir characterization. She is currently working with Schlumberger as a geophysicist.

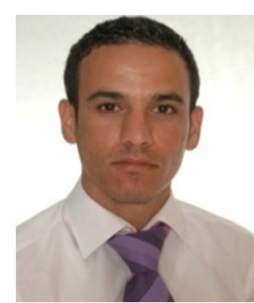

Mohamed Zinelabidine Doghmane was born in 1985 in Bousaada, Algeria. He holds a PhD degree in Electrical Engineering from the Faculty of Hydrocarbons and Chemistry, Unversity M'hamed Bougara of Boumerdes, a Magister degree in Geophysics from IAP, Magister degree in Applied Automatic from the Department of Automation, University of Boumerdes, and an Engineering degree from the Ex-INELEC Boumerdes, Algeria. Now, he is working with SONATRACH (Algerie), and he is a member in research laboratory, University of Boumerdes. His current research interests are reservoir evaluation and optimization of control design for complex systems in petroleum engineering.

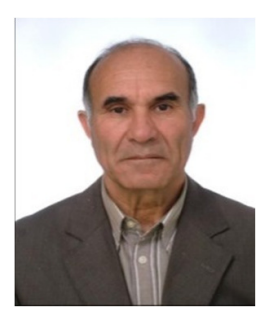

Mabrouk Dejddi was born in Azzaba-Skikda, Algeria. He received an Engineering degree in Geophysics from the Institut National des Hydrocarbures et de la Chimie (INH) -in 1972 and a $\mathrm{PhD}$ from Lomonossov University, Moscow, Russia in 1977 , a $\mathrm{PhD}$ degree from the Faculty of SciencesUniversity of Bordeaux I, France in 1986. He is currently a full Professor at M'hamed Bougara University, Faculty of Hydrocarbons and Chemistry, Department of Geophysics. His domain of research includes stratigraphic seismic, seismic prospection, and signal processing. 